\title{
Modeling of Cavitating Flow through Waterjet Propulsors
}

\author{
Jules W. Lindau, Christopher Pena, Warren J. Baker, James J. Dreyer, \\ William L. Moody, Robert F. Kunz, and Eric G. Paterson
}

Applied Research Laboratory, The Pennsylvania State University, State College, PA 16804-0030, USA

Correspondence should be addressed to Jules W. Lindau, jwl10@arl.psu.edu

Received 5 February 2012; Accepted 12 May 2012

Academic Editor: Yin Lu (Julie) Young

Copyright ( $) 2012$ Jules W. Lindau et al. This is an open access article distributed under the Creative Commons Attribution License, which permits unrestricted use, distribution, and reproduction in any medium, provided the original work is properly cited.

A computational-fluid-dynamics-based modeling effort to capture flow through an axial flow waterjet propulsor is presented. The effort covered the waterjet flow over a wide range of flow coefficients and into cavitation-driven breakdown. The computations are presented in cavitation at two values of flow coefficient through a series of decreasing operating inlet total pressure. The computational results are compared to experimental measurements. Suction-surface and tip-gap cavitation patterns are presented and compared to experimental photographs. Presented computational solutions are blade-passage steady and periodic. The computational results apply a powering iteration methodology to facilitate coupling of rotor, stator, and inflow and outflow ducting.

\section{Introduction}

Axial flow waterjets are a marine propulsion configuration promising to provide a balance between robustness and performance particularly suited to high-speed craft. Due to the contained, internal nature, they may be attractive from a modular vehicle design standpoint. Of course, to achieve performance, they must be integrated with a welldesigned inlet, nozzle, and conformal hull. Due to their internal flow nature, waterjets are expected to maintain resistance to cavitation, are amenable to advanced concepts such as thrust vectoring, should exhibit a wide range of nominally high efficiency, and may hypothetically be implemented in all types of surface and submerged marine vehicles. Seemingly, for surface craft, only the inlet must be submerged. However, cavitation and other considerations may drive duct placement as well.

The flow fields through a waterjet propulsor are, however, inherently unsteady and three-dimensional. Furthermore, all ducted propulsors, such as waterjets, are influenced by numerous interacting shear flows. Relative to flow around open propellers, the effects of hub and drive shaft, ducting and shroud, tip gap, and rotor-stator blade-row interaction tend to increase flow path complexity and decrease peak efficiency. Thus, it is surmised that ducted propulsor performance is more strongly influenced by shear flows, inherent unsteadiness, and interacting vortical structures than open propellers.

For all marine propulsors, cavitation due to local pressure depressions is a persistent condition of interest. Typically, cavitation is a limiting condition on propulsor performance. This may be due to an absolute level of loading that may not be exceeded, resulting in a limit on thrust, that is, thrust breakdown.

Cavitation breakdown, that is, the significant alteration in propulsor torque or thrust due to cavitation, may coincide with cavitation choking, at least for a ducted turbomachine. Cavitation choking is quite similar in manifestation to gasdynamic choking. Using a simple throttling device such as a nozzle, and given an inlet reservoir at a fixed total pressure and temperature, there is a minimum outlet backpressure beneath which further reduction fails to increase the mass flow through the nozzle. For gas dynamics, the maximum mass flow coincides with sonic flow at the nozzle throat. For cavitation, the maximum mass flow coincides with the onset of cavitation at the nozzle throat. The throat is then at a physical minimum operating pressure. Any attempt to increase flow rate, without increasing the nozzle 
total pressure, would cause an increase in the amount of vapor at the throat, reducing the effective flow area, and thus increasing the throat mean velocity, an unsustainable condition. This is described by Mishra and Peles [1]; that is, choking occurs as soon as vapor is present downstream of the nozzle throat. Although they focus on a current research area, microscale nozzles, they point out that the choking event occurs similarly in any size device. A simple description of cavitation choking is also given in Chapter 8 of Brennen [2].

A three-dimensional, multiphase Reynolds-Averaged Navier-Stokes (RANS) computational tool has been applied to axial flow waterjet computations. Previously, Kunz et al. [3] and Lindau et al. [4, 5] have presented steady and unsteady cavitating flow results using the same RANS approach, conserving liquid and vapor phases with transport-based mass transfer. Athavale et al. [6] applied a similar homogeneous RANS approach to an axial flow waterjet, a centrifugal pump, and a rocket pump inducer. Although detailed comparison to experiments was not included, this work demonstrated the applicability of a homogeneous multiphase RANS cavitation modeling approach to ducted turbomachinery. Coutier-Delgosha et al. [7] presented an evaluation of RANS turbulence modeling, including an extension of the $k-\omega$ model for compressible flows. A homogeneous approach with phase change based on a barotropic model was used. Their work suggests improvements to application of turbulence modeling for cavitating flows. The results of Lindau et al. [4] represented the flow of an unducted marine propeller over a wide range of advance ratios from fully wetted operating conditions through cavitation-driven thrust breakdown. Mejri et al. [8] modeled the cavitating flow through rocket pump inducers using a similar homogeneous RANS-based model. Although deficiencies were noted in the model results, it was unclear whether they were due to grid resolution or to the modeling approach itself. Nevertheless, qualitative agreement was found between experiment and computations. In Schroeder et al. [9] a mixture homogeneous RANS based computational solution of flow in a waterjet propulsor is presented over a range of flow rates. Solutions compared favorably to test data. In Lindau et al. [5], steady and unsteady propulsor flows, including non-uniform inflows and waterjet flows were presented. Solutions were obtained using an overset, homogeneous multiphase RANS approach.

In flows modeled here, gas-liquid interface curvatures are small, and pressure and velocity are approximately continuous across the interface. It is therefore presumed that nonequilibrium interface dynamics are of negligible magnitude, and the effect of surface tension is not incorporated. Thus, the large scale of such cavities implies tractability by a homogeneous approach; that is, cavities and features of interest will be resolved with a computational mesh. Nonetheless, such flows are generally unsteady and contain regions of separated flow. For cavitation inception, where physics of tiny bubbles and nucleation is critical, this methodology would not be appropriate. For cloud cavitation, or cases where cavitation is sufficient to effect propulsor hydrodynamic performance, however, this homogeneous, single-fluid, multiphase approach is reasonable.
In any case where multiple blade-row turbomachinery is modeled with CFD, there is a temptation to reduce the complexity and computational solution effort required to solve the problem from the fully unsteady three-dimensional condition. One method of reducing this complexity while still faithfully modeling the three-dimensional blade-row flow physics is a so-called powering iteration. In this approach, each blade-row flow field is assumed periodic, consistent with the number of blades. Periodic computational grids, representative of each blade-row, are thus assembled with sufficient extent to provide reasonable, circumferentially averaged boundary conditions, upstream and downstream of each blade. All blade passages are coupled together, and to the farfield, using a through-flow grid extending to the furthest reaches of the modeled domain. The through-flow grid may be $3 \mathrm{D}$ or axisymmetric depending on the requirements to capture the upstream and downstream flow. In the throughflow grid, the forces and blockages on the flow due to the blades are represented with axisymmetric body forces and blockage terms. These forces are obtained from the 3D blade passage solutions and are included in the physical location of the blade from which they were derived. In cases where blade passage grids must overlap adjacent blade-rows, the overlapped blade-row body forces are included. The iterative part of the approach is due to the need to match a salient quantity from the propulsor solution, such as thrust, to a quantity found from the farfield solution, such as drag. In solutions presented here, the modeled flow is in a tunnel, thus the solution is simply converged by successive updates of the body force and blockage fields until successive iterations result in insignificant flow, body force, and blockage changes.

A number of publications have appeared presenting mass-transfer models that are appropriate for the modeling of large-scale cavitation $[3,10,11]$. All of these models attempt to empirically capture the affect of interface dynamics on mass-transfer while maintaining local mass transfer rates that are dependent solely on the local pressure, and liquid and vapor mass fraction.

\section{Formulation and Solution Method}

To solve the locally homogeneous, multiphase flow conservation equations, a structured, finite-volume formulation with formal third-order spatial accuracy was employed. The differential form of the computational model in Cartesian tensor notation is given in (1). The corresponding conservative variables, primitive variables, flux vectors, and source terms are also defined in (1). The term $\Gamma^{P}$ is a result of the preconditioning approach [12]. Steady cases were modeled in the rotating reference frame and include assumed periodicity about a single-rotor blade. The noninertial, rotating frame term is indicated in the source vector of (1).

To numerically capture very low Mach number, flows, that is, incompressible flows, the inherent decoupling of the physical momentum and continuity equations may be resolved by various strategies [13]. Here, a preconditioner is applied to yield a well-conditioned inviscid eigensystem. The preconditioning matrix $\Gamma^{P}$ appearing in (1) was derived in 
Venkateswaran et al. [12]. The modified inviscid eigensystem then, ideally, dominates convergence of the pseudotime marching system. The coupled equations presented in (1) are termed isothermal. The isothermal form admits compressibility of the liquid and gas species, but only as each species density may be a function of one independent variable, the local pressure. Thus each phase or species is assumed to have a constant sound speed. However, the mixture sound speed (and density) is strongly dependent on the local volume fraction composition. A total energy conserving extension, one admitting dependence of properties on temperature, of the present formulation has been similarly derived [14] and is useful in consideration of extremely high-speed flows and other thermal effects. Solutions presented here either assume infinitesimal $\left(10^{-15}\right)$ or very small (but physically correct) free-stream Mach numbers. For steady computations at the low physical free stream Mach number conditions considered, the effect of compressibility is expected to be insignificant. However, it is expected that, even for very small free stream speeds, unsteady cavitating computations may be affected by compressibility [12]. For typical cloudcavitating flows, compressibility will affect the dynamics of the reentrant jet and is required to capture the dynamics of cavity collapse and shocks that form near the closure. To capture such unsteady events with high fidelity in a numerical framework similar to that presented here, researchers have neglected physical dissipation modeling entirely, relying on numerical diffusion (i.e., the numerical flux- and grid-based truncation error) to provide sufficient dissipation [15]. Based on previous work $[3,4,21]$, when searching with a RANS method with sufficient resolution for the average forces on turbomachinery and the mean cavity size, it is anticipated that much of the unsteadiness and compressible effects may be neglected:

$$
\begin{aligned}
& \Gamma^{p} \frac{\partial Q}{\partial \tau}+F_{j, j}-F_{j, j}^{v}=H, \\
& Q=\left[\begin{array}{c}
p \\
u_{j} \\
\alpha_{v}
\end{array}\right], \quad Q=\left[\begin{array}{c}
\rho \\
\rho u_{j} \\
\rho \alpha_{v}
\end{array}\right], \quad F_{j}^{v}=\left[\begin{array}{c}
0 \\
t_{i j} \\
0
\end{array}\right] \text {, } \\
& H=\left[\begin{array}{c}
0 \\
-\rho\left[\varepsilon_{i j k} \omega_{j} \varepsilon_{k l m} \omega_{l} x_{m}-2 \varepsilon_{i j k} \omega_{j} u_{k}\right]+f_{j} \\
-\left(\dot{m}^{+}+\dot{m}^{-}\right)
\end{array}\right] .
\end{aligned}
$$

Note that the momentum conservation includes source terms represented reference frame rotation and other body forces $\left(f_{j}\right)$. It is convenient in the formulation used here to present continuity in the form of a mixture mass conservation law. This is apparent in (1). For all results presented here, only two phases are considered, a liquid and a vapor. Therefore, the subscript $l$ is used to refer to liquid and $v$ refers to vapor. Note also that the vapor massconservation equation contains a mass-transfer source term $\left(\dot{m}^{+}+\dot{m}^{-}\right)$. When other gases or liquids are modeled as part of the local mixture, their inclusion, in the form of (1), is straightforward. The mixture density is defined based on the local volume average density:

$$
\rho=\alpha_{v} \tilde{\rho}_{v}+\alpha_{l} \tilde{\rho}_{l}
$$

The viscous stress tensor takes on the usual form for the mixture:

$$
t_{i j}=\mu_{m, t}\left(u_{i, j}+u_{j, i}-\delta_{i j} \frac{2}{3} u_{k, k}\right)
$$

In (4), necessary mixture turbulent and molecular viscosities are defined. Where applied, the subscript $m$ indicates a liquid-gas mixture quantity. As is sensible, the mixture molecular viscosity is based on a local volume average. The eddy viscosity is defined to be consistent with the locally homogeneous mixture assumption:

$$
\mu_{t}=\frac{\rho C_{\mu} k^{2}}{\varepsilon}, \quad \mu_{m}=\alpha_{l} \mu_{l}+\alpha_{v} \mu_{v}, \quad \mu_{m, t}=\mu_{m}+\mu_{t} .
$$

A two-equation turbulence closure model is employed (5). At each pseudotime step, these are solved in a coupled fashion but segregated from the flow equations. A hybrid wallfunction model based on the work of Spalding [16] is also employed. With this approach, a range of near-wall spacing from the log-layer down to the viscous sublayer should be acceptable. For solutions containing sublayer grid resolution, a damping parameter controls the modeled production and eddy viscosity in near-wall regions of the flow. Otherwise, it approaches unity [17]. Standard values for other constants, $C_{1}$ and $C_{2}$, are applied [18]:

$$
\begin{gathered}
\frac{\partial Q_{T}}{\partial \tau}+\frac{\partial F_{j}^{T}}{\partial x_{j}}=\text { PROD }- \text { DEST } \\
Q_{T}=\left[\begin{array}{c}
\rho k \\
\rho \varepsilon
\end{array}\right], \quad F_{j}^{T}=\left[\begin{array}{l}
\rho k u_{j}-\left(\mu_{m}+\frac{\mu_{t}}{\sigma_{k}}\right) \frac{\partial k}{\partial x_{j}} \\
\rho \varepsilon u_{j}-\left(\mu_{m}+\frac{\mu_{t}}{\sigma_{\varepsilon}}\right) \frac{\partial \varepsilon}{\partial x_{j}}
\end{array}\right], \\
\operatorname{PROD}=\left[\begin{array}{c}
1 \\
C_{1} \frac{\varepsilon}{k}
\end{array}\right] \rho \tau_{i j} \frac{\partial u_{i}}{\partial x_{j}}, \quad \text { DEST }=\left[\begin{array}{c}
\rho \varepsilon \\
C_{2} \rho \frac{\varepsilon^{2}}{k}
\end{array}\right] .
\end{gathered}
$$

The transfer of mass between liquid and vapor states is handled with simple finite-rate relations $\left(\left(\dot{m}^{+}+\dot{m}^{-}\right)\right.$in $\left.(1)\right)$. For results presented, the Kunz model [3] is applied to provide the mass-transfer terms in (1). A number of masstransfer models for transport-based, locally homogeneous RANS modeling of cavitating flow have been introduced in the literature. Although these models are similar in their algebraic form, it is worth noting that Morgut and Nobile [19] attempted to fairly compare and evaluate their differences and similarities in numerical practice. Their conclusions suggest that there is little difference in the expected result with these models. However, proper application of the models and choice of their constant coefficients matter greatly. In the Kunz model, presented in (6), it is proper to 
state that a nucleation process, only limited by the resolution of the computational mesh, is assumed, while vapor growth is constrained to occur on a time and length scale determined from the resolved physics of the flow. Condensation similarly occurs on a time scale determined by the presumed physics of the flow and interfacial area. For turbomachinery problems, a time scale, $t_{\infty}$, is determined from the mean convective velocity and the blade leading-edge radius. The remaining coefficients are specified as $C_{\text {dest }}=1.0$ and $C_{\text {prod }}=\rho_{v} / \rho_{l}$ :

$$
\dot{m}^{+}=\frac{C_{\text {dest }} \rho_{v} \alpha_{l} \operatorname{MIN}\left[0, \rho-\rho_{v}\right]}{(1 / 2) \rho_{\infty} U_{\infty}^{2} t_{\infty}}, \quad \dot{m}^{-}=\frac{C_{\text {prod }} \rho_{v} \alpha_{v} \alpha_{l}^{2}}{t_{\infty}} .
$$

\section{Results}

Computational results have been obtained for an axial flow waterjet. Experimental data, in the cavitation tunnel, has been documented over a range of single-phase and cavitating conditions [20]. The waterjet is computationally modeled in a fashion approximately representative of the cavitation tunnel experiments. In typical water-tunnel experiments, to capture cavitation breakdown, the rotational speed and flow rate are held as close to specified values as possible while the absolute test pressure is modulated. In this way, the parametric effect of cavitation number (for a surface craft, free stream speed, and suction head) on operation may be investigated while other specific operating conditions are held constant. The operating conditions of interest are a given flow coefficient (i.e., relative blade leading-edge flow angle) and Reynolds number. Numerical results were first obtained at single-phase operating conditions at the given flow coefficient and Reynolds number. Subsequently cavitating solutions were found using the initial conditions first obtained at single phase. As lower cavitation-number conditions were computed, the initial conditions used were typically those at the previous, slightly higher, cavitation number, and the same flow coefficient. As all of the solutions presented here were obtained using a steady RANS form, initial conditions were initial in a numerical sense only. Computations were not time accurate.

It should be noted that tunnel conditions tended to break down at severe cavitation and the computational results were not kept entirely faithful. In order to model the actual flow rates for a given cavitation condition, as occurs in the given water tunnel, with greater fidelity, one would need to include a representation of the flow features of the entire tunnel, and allow the flow rate to adjust accordingly. Thus at severe breakdown, Reynolds number and flow coefficient were only matched with a select number of experimental cases. However, as will be seen, the initiation of breakdown and its general flow features are still quite well captured. In fact, by gridding the full tunnel flow path, using the powering iteration method, the effect of the water tunnel and the fully coupled flow relations could be automatically captured. Here only the prescribed flow coefficients, as would be expected during the desirable type of propulsor testing, were captured. For all modeled cases, the flow is treated as fully turbulent. The waterjets are modeled, at prescribed flow coefficients, from on-design to the cavitation-driven thrust breakdown condition.

As has been stated, computational results presented here are based on solution of a steady form of the governing equations. Although a time-marching method is applied, it is marched in pseudotime and time-accurate results were not obtained. At limiting conditions of the flow, when steady solution integration failed, it is likely that unsteady integration could be applied to further investigate the nature of the flow which itself is expected to be largely unsteady. Unsteadiness is particularly expected when large vaporous regions appear in the solution causing large vortical structures to be shed along with vapor. It is tempting to investigate such large-scale cavity unsteadiness, such as has been done by [21] using a Detached Eddy Simulation approach. However, it would seem that for rotating machinery, any investigation of flow unsteadiness should include the unsteady rotor-stator interaction. This is expected to require an unsteady solution of all blade passages in the full turbomachine without periodic assumptions.

3.1. AxWJ-2 Waterjet Pump. An axial flow waterjet pump (AxWJ-2) has been designed, fabricated, and tested by researchers from Johns Hopkins University and the Naval Surface Warfare Center Carderock Division (NSWCCD). Measurements of the total head rise and shaft torque on flow through the pump have been taken at a range of flow conditions through cavitation breakdown [20]. The singlephase and cavitating flow through this pump has been computationally modeled. Results are presented here for a single rotor-blade passage. For all conditions presented here, the stator row is modeled with body forces and blockage terms. A powering iteration was used to fully couple the axisymmetric tunnel flow, the three-dimensional rotor, and three-dimensional stator computational flows. Thus the correct, mean, and integrated effects of test-section inlet boundary layers, stator flow turning, stator blockage, and test section outlet diffusion, and boundary layers are, for instance, captured on the rotor flow. However, these effects are circumferentially averaged, and only cavitation in the rotor flow passage is modeled.

3.2. Mesh and Single-Phase Results. In Figure 1, the computational grids used to obtain the RANS evaluation of the waterjet flow are presented. The grids pictured comprise the elements of the powering iteration strategy. The word powering is used because the same methodology may be applied to obtain the correct operating conditions for an installed propulsor on a vessel. Then the shaft power required to propel the vessel would be computationally determined. The approach as applied here attempts to properly couple flow in the three pictured grids. For this water tunnel configuration, it is assumed that the flow is reasonably assumed to be axisymmetric, a short distance upstream and downstream of the waterjet pump. Therefore, to couple the three-dimensional, but steady, and periodic flow about the rotor and the stator, to each other, and to the upstream and downstream tunnel flow, an axisymmetric grid and flow 


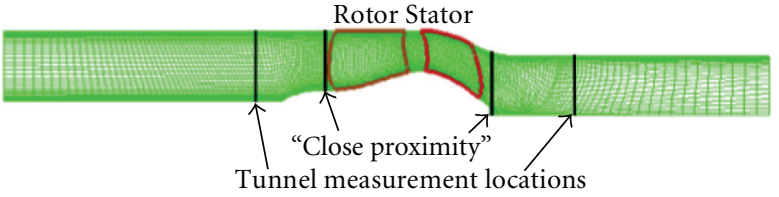

(a)

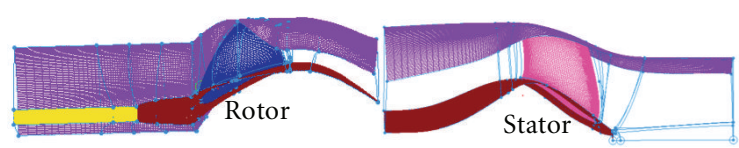

(b)

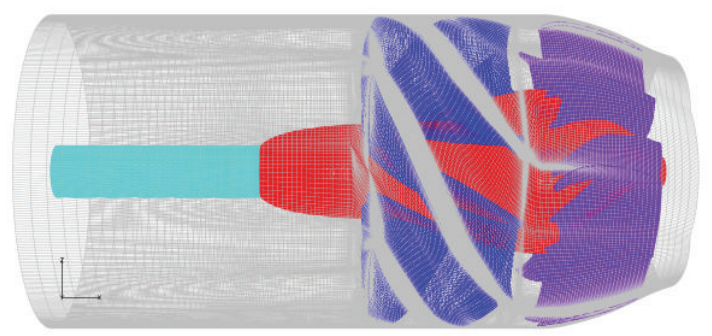

(c)

Figure 1: Waterjet pump, AxWJ-2, computational grids shown on all solid surfaces. (a) Axisymmetric through-flow grids with "measurement" locations illustrated. (b) Periodic 3D rotor, and 3D-stator grids. (c) 3D grids assembled, repeated, and overlaid for illustration. In part (c), shaft is light blue, hub is red, rotor blades are dark blue, stator blades are purple, and shroud/duct is gray.

solution is appropriate. Solution on the through-flow grid, Figure 1(a), provides inflow velocity and outflow pressure profiles to the rotor and stator grids, pictured in Figure 1(b). In the through-flow grid solution, body forces equal to circumferentially summed forces on the rotor and stator blades are applied. The forces on the rotor and stator blades are found from solution of the three-dimensional periodic flow determined on the computational meshes in Figure 1(b). In Figure 1(a), the forces due to the rotor and the stator are applied in the corresponding labeled, outlined regions. The iteration involves successive solution of the flow on the three meshes. After each solution, an update of inflow velocity and outflow pressure profiles (obtained from the through-flow mesh, Figure 1(a)) and body forces (obtained, resp., from the rotor and stator meshes, Figure 1(b)) is made. The iteration is complete when the updated profiles do not change significantly with successive iterations.

Experimental measurement locations are also roughly indicated on the through-flow grid, Figure 1(a). In the case of modeling a tunnel flow, the axisymmetric through-flow grid is primarily used to obtain realistic inlet velocity profiles and exit pressure profiles, both as functions of radius, for the rotor and stator flow domains. In addition, the through-flow grid is used to obtain integrated performance information for the waterjet, such as head rise. The rotor and stator flow

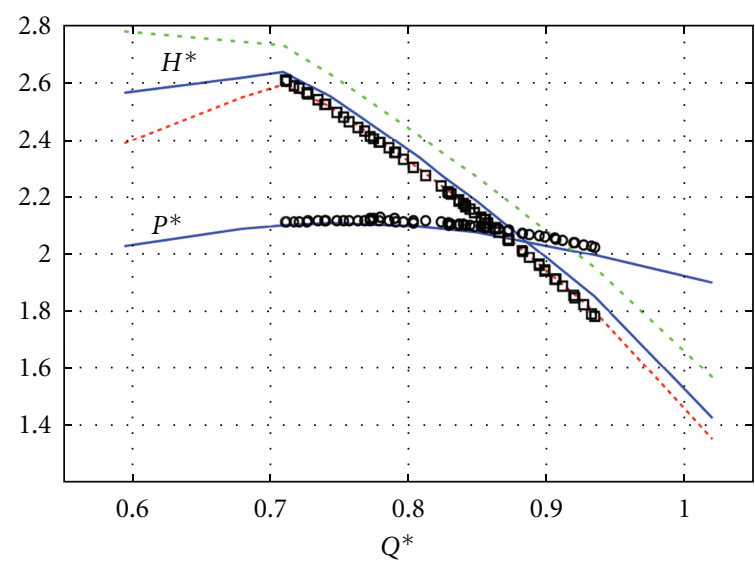

$$
\begin{array}{llll}
- & H^{*} \mathrm{CFD} & \cdots & H^{*} \mathrm{CFD} \text { (close proximity) } \\
- & P^{*} \mathrm{CFD} & \square & H^{*} \mathrm{EFD} \\
\cdots \cdots & H^{*} \mathrm{CFD} \text { (slug flow) } & \circ & P^{*} \mathrm{EFD}
\end{array}
$$

Figure 2: Single-phase flow. Waterjet pump, AxWJ-2, powering iteration integrated results. Dimensionless power $\left[P^{*}=\right.$ (Power) $\left./\left(\rho n^{3} D^{5}\right)\right]$ and head rise $\left[H^{*}=g H /\left(n^{2} D^{2}\right)\right]$ versus flow rate $\left[Q^{*}=Q /\left(n D^{3}\right)\right]$.

domains each contain approximately 2 million grid points. The rotor grid includes the tip-gap region. To accommodate the close proximity of the rotor and stator blades, it is necessary that the rotor grid overlap the stator passage and vice versa. This allows the necessarily axisymmetric outflow boundary to be located further downstream of the rotor passage exit, yielding a more proper wake flow and loading of the rotor blade than the typical mixing plane boundary condition. Thus the region of the rotor blade grid overlapping the stator blade region contains the stator blade body forces and blockages.

In Figure 2, alongside experimental measurements (EFD) from the NSWCCD $0.9144 \mathrm{~m}$ (36 in) water tunnel, the single-phase computational-fluid-dynamics- (CFD-) based performance, in terms of power and head-rise coefficient of the modeled $\mathrm{AxWJ}-2$, is given over a range of flow coefficients. The performance is presented in terms of dimensionless flow rate, $Q^{*}=Q /\left(n D^{3}\right)$, head rise, $H^{*}=g H /\left(n^{2} D^{2}\right)$, and power, $P^{*}=P /\left(\rho n^{2} D^{5}\right)$. The CFD head-rise results are given using three different measurement locations and integration assumptions. A maximum head rise, based on integrated total pressure (at locations indicated in Figure 1) is given using closeproximity integration surfaces. A fully integrated head rise based on surfaces at the correct water-tunnel measurement locations is also given. Finally, a constant velocity profile (i.e., slug flow) assumption-based head rise also using the correct water-tunnel pressure measurement locations is given. Note that computed performance based on the appropriate measurement locations, with slug flow assumptions, yields computed head rise and power both in excellent agreement with the EFD. Clearly, the non-isentropic effect of mixing is evident in the CFD and measured water-tunnel results. The computed head rise was quite sensitive to the chosen 


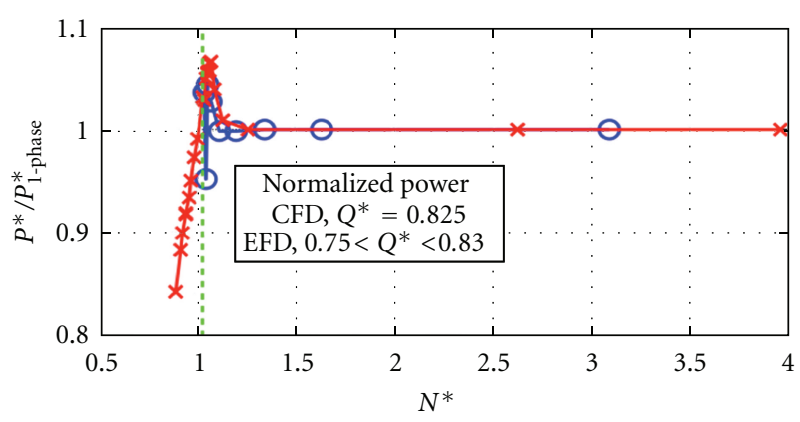

(a)

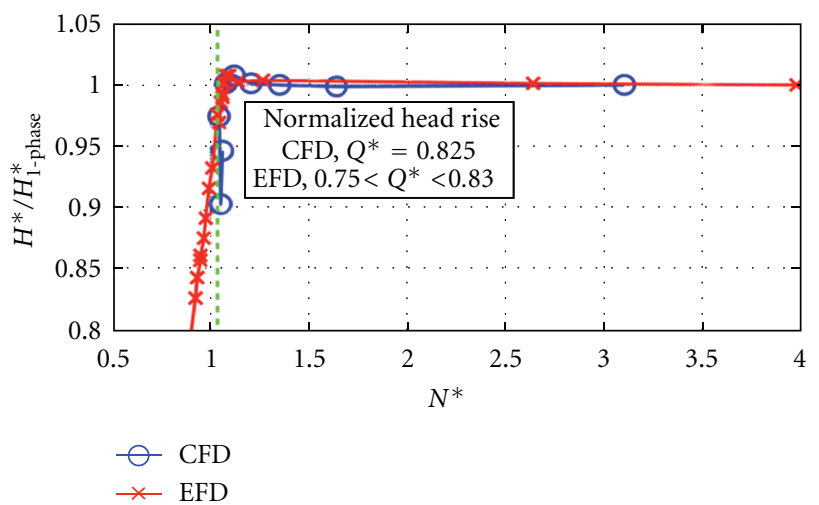

(b)

FIGURE 3: Waterjet pump, AXWJ-2, cavitating-RANS integrated results at constant $Q^{*}=0.825$ into breakdown presented with EFD of similar conditions $\left(Q^{*}=0.83\right.$ prior to breakdown, $Q^{*}$ drops precipitously in breakdown $) . N^{*}=\left(p_{0 \text { in }}-p_{v}\right) /\left(0.5 \rho_{\infty} n^{2} D^{2}\right)$. Results from $3 \mathrm{D}$ multiphase rotor computations with circumferentially averaged inflow and outflow boundary conditions. Body forces derived from $3 \mathrm{D}$ stator RANS represent stator forces. Note that the normalization is with respect to the single-phase flow at the corresponding $Q^{*}$. $Q^{*}$ is constant for the CFD but varies in the experimental data.

CFD measurement locations (indicated in Figure 1). The quoted physical measurements were based on tunnel-wall static-pressure taps and slug flow assumptions. Thus, similar assumptions must be made for purposes of comparison to the tunnel testing when head rise is estimated from the CFD. These results and understandings of the watertunnel measurement procedures were aided by guidance from NSWCCD researchers. Finally, note that at low flow rates and high blade loading conditions, outside the range of performance reported in Chesnakas et al. [20], the computed flow appears to break down due to massive suction side flow separation (stall).

3.3. Cavitation Breakdown. In Figures 3 and 4, the integrated effects of cavitation breakdown are plotted in terms of $H^{*}$ and $P^{*}$ as dependent on an inflow cavitation coefficient, $N^{*}=\left[\left(P_{0 \text { in }}-P_{v}\right) /\left(\rho n^{2} D^{2}\right)\right]$. CFD is presented with EFD. Results for nominally two flow coefficients $\left(Q^{*}=\right.$ 0.825 and $\left.Q^{*}=0.71\right)$ are presented. However, the EFD results contain a range of flow coefficients as the mass flow

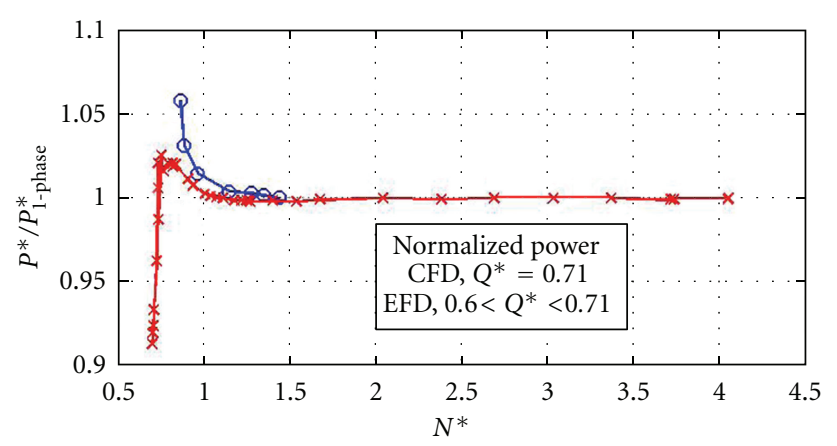

(a)

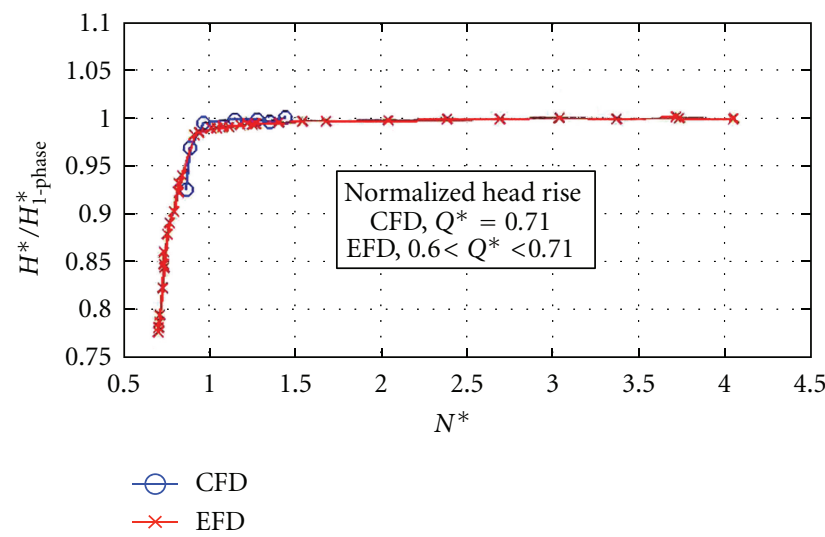

(b)

FIGURE 4: Waterjet pump, AXWJ-2, cavitating-RANS integrated results at constant $Q^{*}=0.71$ into breakdown presented with EFD of similar conditions $\left(Q^{*}=0.71\right.$ prior to breakdown, $Q^{*}$ drops precipitously in breakdown $) . N^{*}=\left(p_{0 \text { in }}-p_{v}\right) /\left(0.5 \rho_{\infty} n^{2} D^{2}\right)$. Results from $3 \mathrm{D}$ multiphase rotor computations with circumferentially averaged inflow and outflow boundary conditions. Body forces derived from $3 \mathrm{D}$ stator RANS represent stator forces. Note that the normalization is with respect to the single-phase flow at the corresponding $Q^{*}$. $Q^{*}$ is constant for the CFD but varies in the experimental data.

through the propulsor is dependent on the resistance and pumping power of the entirety of the tunnel. Thus, the EFD data contains dropping flow rates as the tunnel pressure is decreased and the cavitating flow breaks down. Clearly the performance and the initial peak in power with decreasing cavitation number are well captured by the CFD. In Figure 3, at the higher relative flow rate, $Q^{*}=0.825$, the complete picture of power increase and decrease in breakdown is captured. There is a difference in the absolute peak in power as the tunnel pressure is decreased, but the overall agreement, especially considering the differences in flow rate as the tunnel flow breaks down, is good. However, the computed solutions at the higher loading condition, $Q^{*}=0.71$, in Figure 4 were somewhat more divergent (in torque) from the EFD data. Subsequent to massive cavitation (as the EFD flow rates dropped precipitously at breakdown), the computed power simply increased in value as pressure was reduced. Further computations at lower tunnel pressures were not completed. Note that the divergence of EFD and CFD in 

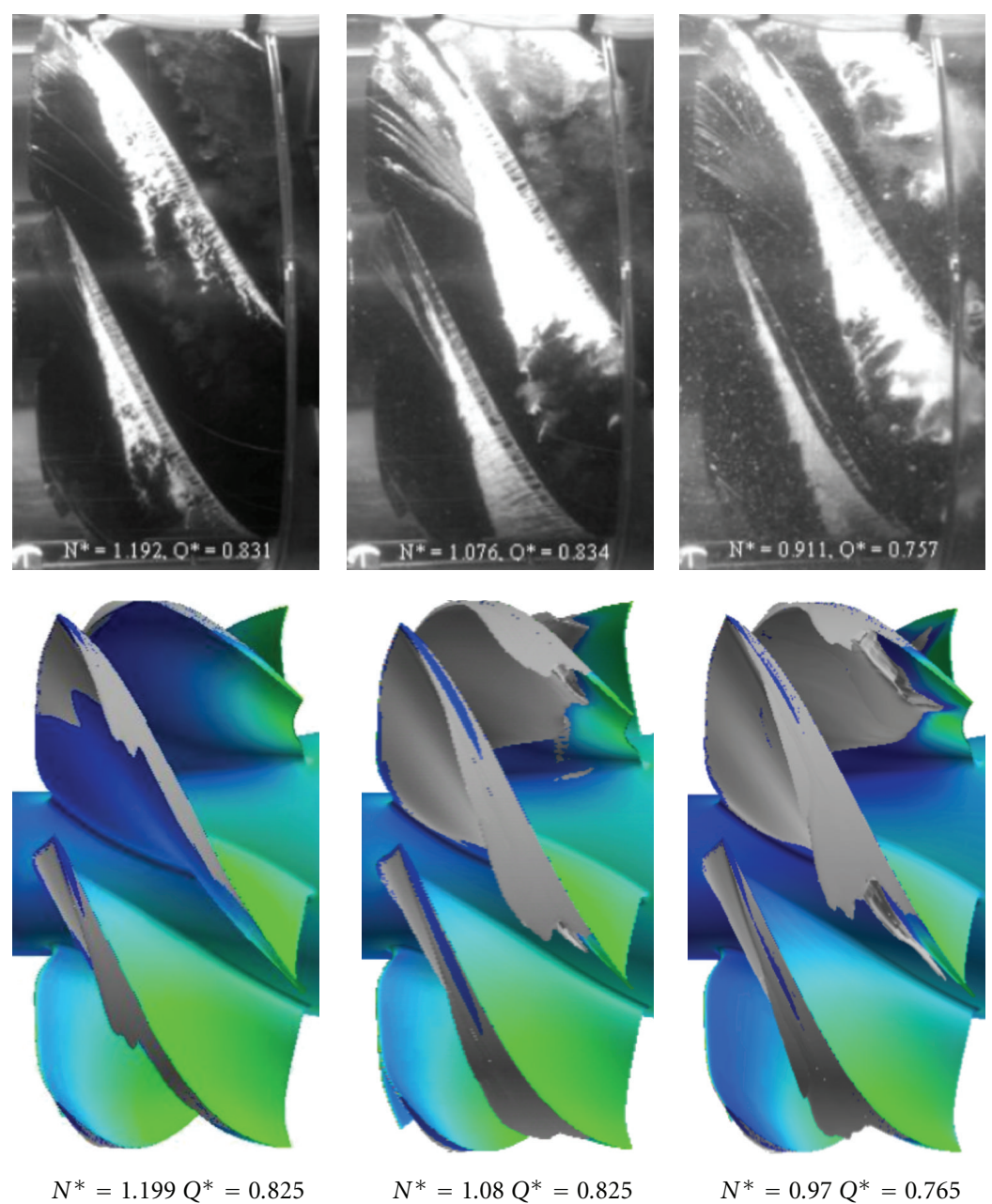

FIGURE 5: Waterjet pump, AXWJ-2, tip leakage cavitation patterns. Photographs from testing [20] with transparent shroud and results from RANS-based modeling (shroud not shown). Solutions are colored by pressure on surfaces. Cavitation is illustrated with $\alpha_{v}=0.5$ isosurface.

breakdown is also due to the drop in tunnel flow rates $\left(Q^{*}\right)$ as vapor formation restricts the flow.

In Figure 3, at cavitation numbers lower than approximately $N^{*}=1.03$ (indicated by dashed green line in the figure), the higher flow coefficient $\left(Q^{*}=0.825\right)$, lighter blade loading condition, differences between computations, and experiment are evident due to differences in flow rate at the low cavitation number conditions. In the EFD, there is no data with a $Q^{*} \geq 0.825$ at $N^{*}<1.03$. Thus, this is indicative of a limiting value in the data, as it appears to also be in the CFD. This limitation is manifested in the CFD results in which it was not possible to converge a steady solution at a lower tunnel pressure while still maintaining the flow rate $\left(Q^{*}=0.825\right)$. It is likely that vapor formation is choking the flow.

Finally, at both the normal and higher loading flow coefficients $\left(Q^{*}\right.$ in Figures 3 and 4$)$, dimensionless head rise (equivalent to thrust) appears well captured, even in breakdown as the CFD and EFD flow rates diverge.

In Figure 5, photographs from Chesnakas et al. [20] and results from CFD cavitating conditions are presented together in a way meant to highlight cavitation in the tipgap region. It is noted that in the presented comparison (Figure 5) the agreement of modeled cavitation across the tip gap including the leakage vortex-influenced cavitation appears quite good. Note that the photographs were made via a polycarbonate window contoured to match the pump casing. In the tip-gap region, approximately 14 computational cells were applied between tip and casing and 42 were used to span the blade thickness.

In Figure 6, CFD and EFD rotor suction-surface cavitation patterns are compared at two tunnel-pressure conditions both at roughly the same highly loaded flow coefficient $\left(Q^{*}=0.71\right)$. Again, the EFD photographs are from Chesnakas et al. [20]. The computed patterns are illustrated with a constant isosurface of vapor volume fraction equal to 0.5 . As was seen in the tip-gap region, the agreement between computed and EFD suction-surface cavity pattern is quite good.

3.4. Cavitation Choking. In the case of cavitating flow in the waterjet, it is suggested that a minimum flow area exists 

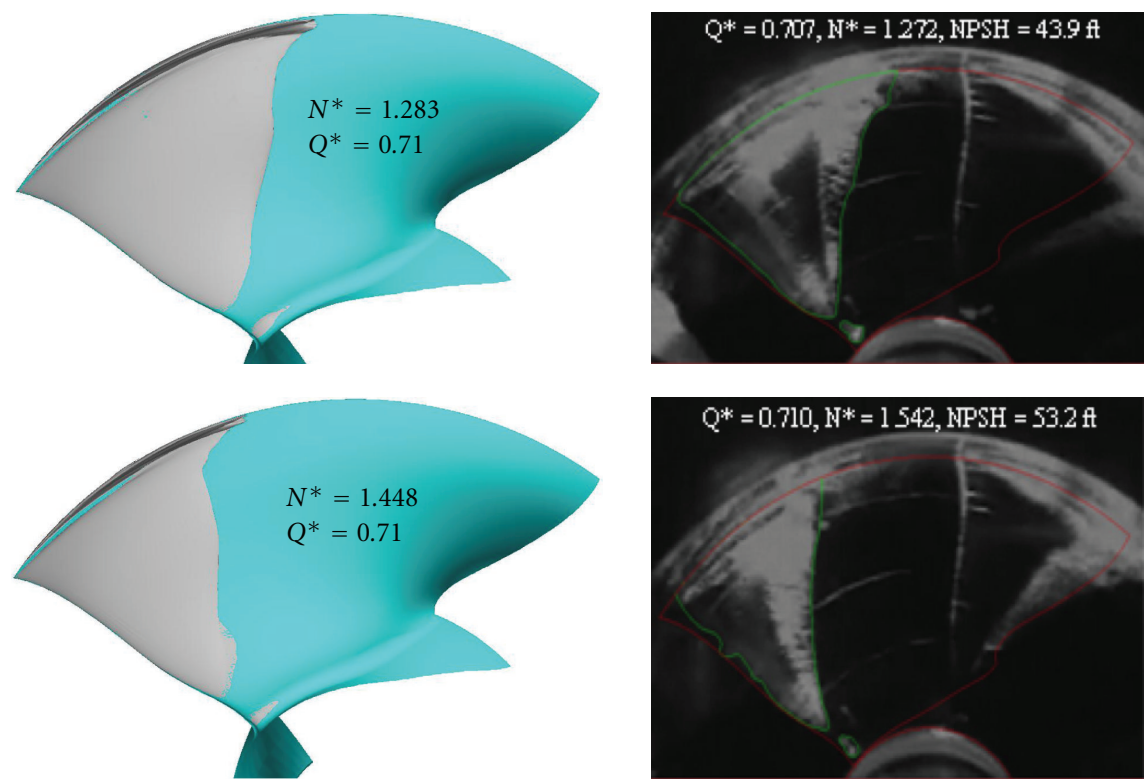

Figure 6: Waterjet pump, AXWJ-2, rotor suction-surface cavitation patterns. Photographs from testing [20] and results from RANS-based modeling. Cavitation is illustrated with $\alpha_{v}=0.5$ isosurface.

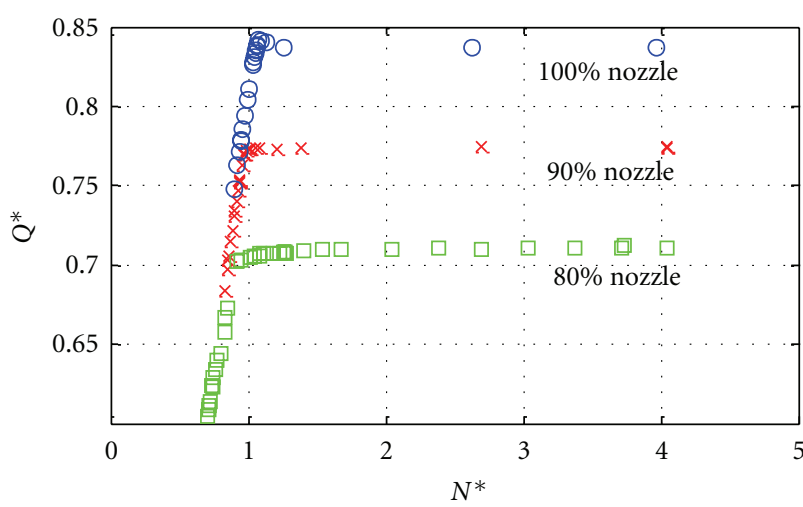

Figure 7: Experimental results [20]. Three different nozzle constrictions were set downstream of the waterjet. $100 \%$ nozzle, $90 \%$ nozzle, and $80 \%$ nozzle. Each of the nozzle settings resulted in a different single-phase $Q^{*}$ condition.

near the rotor passage exit resulting in a vena contracta effect. The minimum flow area is then a simple curved surface, a hypothetical boundary spanning the rotor passage at the vena contracta location. Due to the fact that real turbomachine flow is unsteady and three-dimensional, it will be difficult to precisely define this surface. However, it is a useful, applicable model. Considering the flow through the rotor passage, the mean (area averaged) static pressure will be a minimum at this vena contracta. Thus if operating (rotor inlet total) pressure is gradually reduced, the location of minimum flow area must (eventually) contain an area of cavitation that will grow. Due to local differences in flow turning within the rotor passage, such as at the suction peak of the rotor blade, cavitation may exist in other regions prior to developing at the vena contracta. However, when significant cavitation reaches the vena contracta, this coincides with cavitation choking.

Figure 7 contains experimentally obtained results from Chesnakas et al. [20]. Results were obtained with three different downstream nozzle openings, resulting in three different nominal flow rates (for single-phase flow). Thus prior to vapor formation, the limiting flow feature occurs at the downstream nozzle constriction, labeled in Figure 7, as $100 \%$ (no constriction), 90\%, and 80\% nozzles. Nondimensional flow rate, $Q^{*}$, is plotted against $N^{*}$, a form of inlet cavitation number, or tunnel inlet pressure. At the limiting (minimum $N^{*}$ ) inlet pressure condition, these results appear to illustrate the choking phenomenon as observed in the test data. Note that, as $N^{*}$ is reduced below a value near 1.1 , measured flow rate drops precipitously. At higher values of $N^{*}$, three distinct flow conditions $\left(Q^{*}\right)$ exist, but the results collapse to a near vertical grouping as $N^{*}$ (inlet total pressure) is reduced. This suggests that as the pump is run and pressure is dropped, vapor forms at a critical location. Thus the limiting flow condition exists within the rotor and stator blade sections rather than at the downstream nozzle constriction. This is consistent with cavitation choking.

Figure 8 contains computational and experimental results at a nominal flow rate, $Q^{*}=0.825$. Those results are presented in terms of power coefficient as it varies with inlet total pressure, that is, $N^{*}$. Computational results reach a limit at $N^{*} \approx 1.05$. Converged solutions could not be obtained at lower values of $N^{*}$ for the given flow coefficient. This coincides with cavitation choking in the computational domain. The experimental results do include flow at lower values of $N^{*}$. However, as noted and seen in Figure 7, the experimental $Q^{*}$ drops precipitously at $N^{*}<1.1$ essentially running up against the choked condition. 


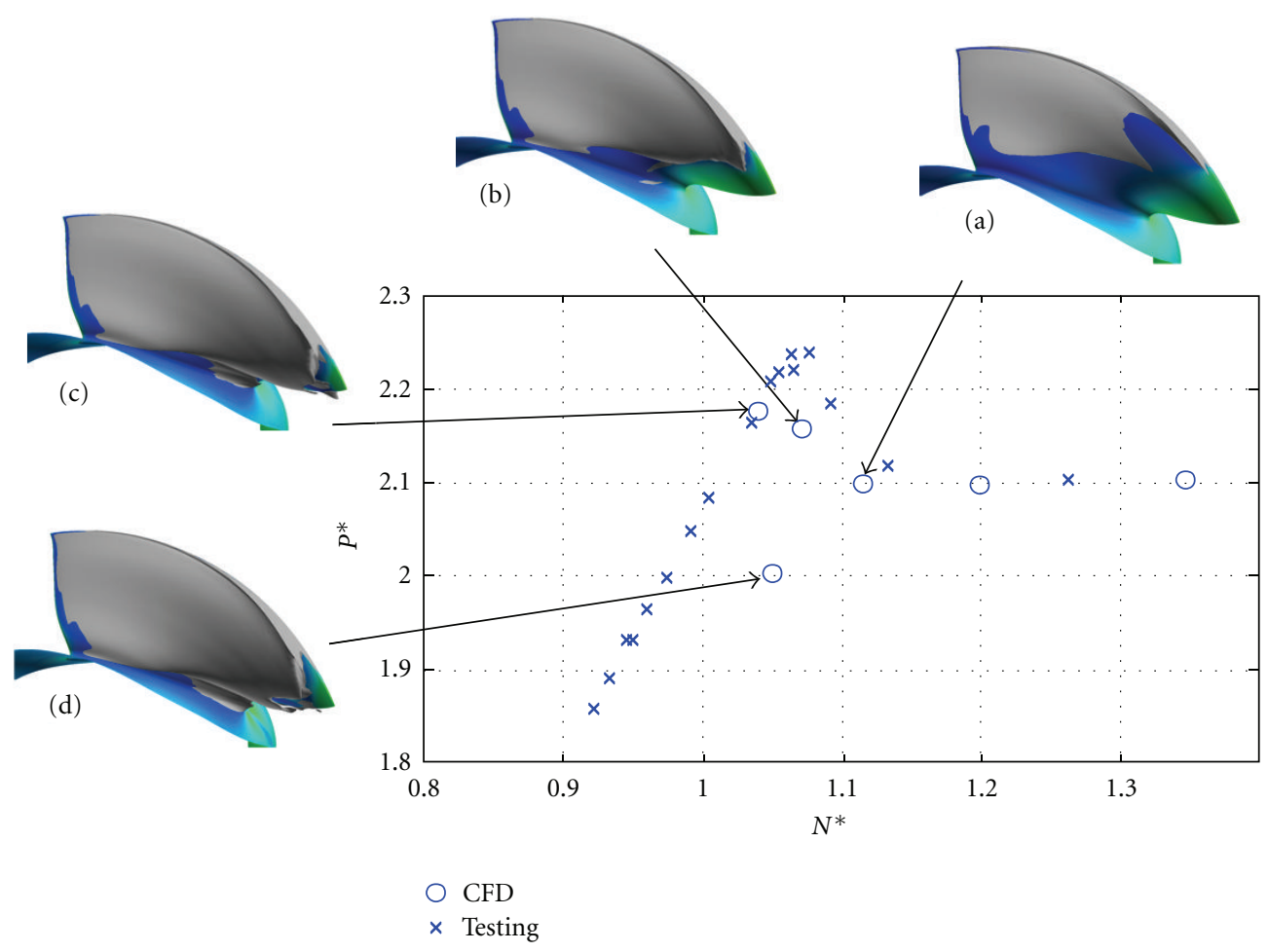

Figure 8: Computational results, breakdown at nominal flow rate, $Q^{*}=0.825$. Experimental results, flow at roughly constant $Q^{*}=0.825$ for $N^{*}>1.1$ but flow rate decreases at lower values of $N^{*}$. Illustrations from CFD results at each of four points, (a) $\left(N^{*}=1.1149\right)(\mathrm{b})$ $\left(N^{*}=1.0699\right)(\mathrm{c})\left(N^{*}=1.0392\right)(\mathrm{d})\left(N^{*}=1.0497\right)$, prior to and after breakdown. Isosurface of vapor volume fraction equal to 0.5 illustrates extent of cavitation along the suction surface of the rotor blade at each of the four conditions.

Computational results illustrating the cavity size and shape along the suction surface of the rotor blade are also shown in Figure 8. Four conditions spanning the breakdown are presented. Condition (a) corresponds to $N^{*}=1.1149$ and is prior to breakdown. (b) is at $N^{*}=1.0699$ and exhibits the power rise due to significant cavitation but does not appear to be choked. (c) is at $N^{*}=1.0392$ and (d) is at $N^{*}=1.0497$. The conditions at (c) and (d) are both apparently choked, and in breakdown. Based on the unsteady nature of real flow at this condition, both (c) and (d) approximate the limiting value of $N^{*}$ (using a steady-RANS method) for a given inlet total pressure and the specified rotation and flow rate. Note, in Figure 8, the size of the vapor region along the rotor surface. It is denoted by the $50 \%$ vapor volume fraction isosurface. At condition (a), the region of vapor is close to the rotor suction surface, has little thickness, and terminates between $1 / 2$ and $3 / 4$ of the blade chord. Although there is significant cavitation, there is little change in performance (considering power, i.e., torque) from the single-phase conditions. The lack of thickness to the cavity region suggests that there is little change (from single phase) in mean flow turning and hence little change in torque or power. At condition (b) the cavity thickness seems more significant resulting in an increase in torque. However, the cavity terminates prior to reaching the end of the blade suction surface. At conditions (c) and (d) the cavity has significant thickness and there is significant cavitation reaching the trailing edge of the rotor blade. These conditions correspond to breakdown and cavitation choking. It is suggested that the cavitation reaching the trailing edge represents a flow blockage or constriction at the vena contracta (minimum rotor flow area). Hence, a further reduction in inlet total pressure at the given conditions of rotation and flow rate is not sustainable.

Several more figures are included to support the assertion that at conditions (c) and (d) of Figure 8, cavitation choking appears to exist, and it is manifested due to conditions at the exit of the rotor passage. In Figures 9-11, results from operating conditions (a)-(d) are presented in terms of vapor volume fraction and local cavitation number, $\sigma_{N}=(p-$ $\left.p_{v}\right) /\left(\rho n^{2} D^{2}\right)$. The results are given on constant radius cuts through the rotor passage. In Figure 9, a cut at $53 \%$ of the shroud radius, close to the hub (at least at the rotor passage exit), is presented. The upper part of the figure contains the vapor volume fraction plot. Note that at the highest $N^{*}$ condition, (a), in this plot, no cavitation is evident. At condition (b), cavitation is evident up to approximately mid chord. At conditions (c) and (d), cavitation reaches the trailing edge of the blade. The lower part of the figure contains the local cavitation number plots. Note that the purpose of plotting this quantity is to indicate when the exit region of the rotor passage is at a saturated pressure; that is, at that point, the flow is choked. 


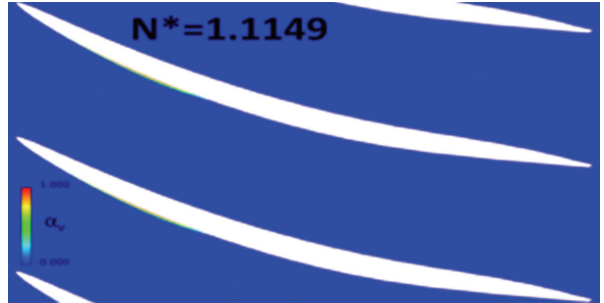

(a)

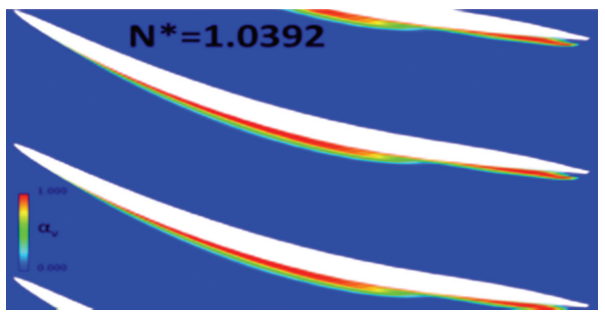

(c)

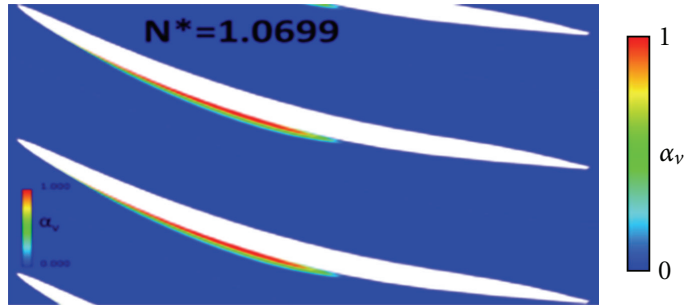

(b)

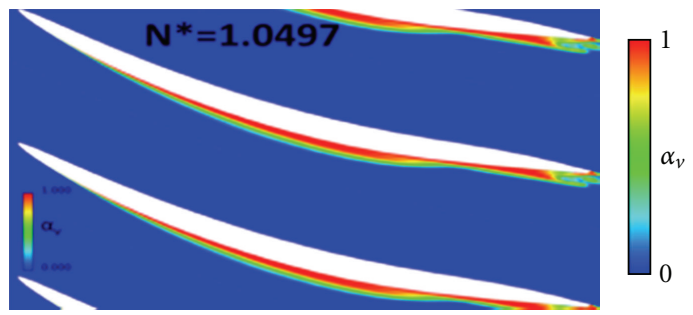

(d)

(A) Contours of vapor volume fraction

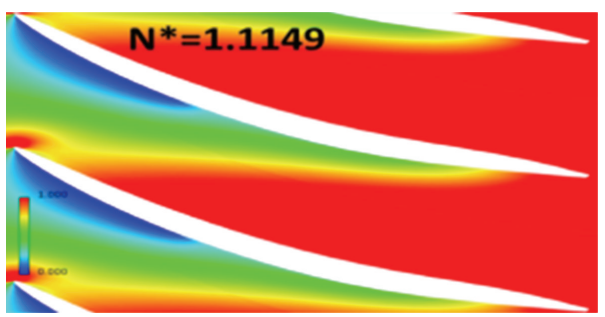

(a)

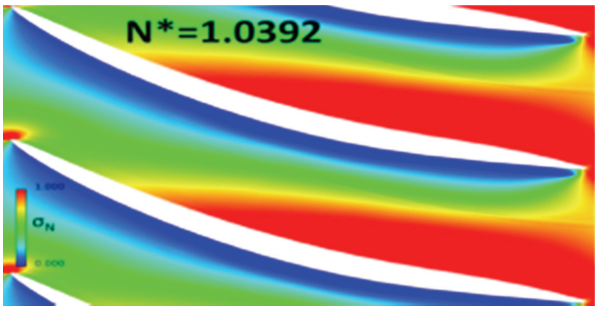

(c)

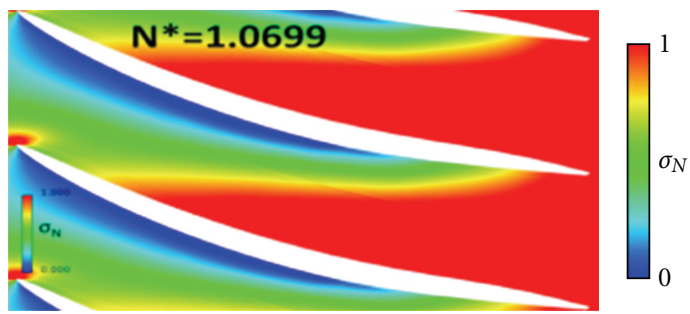

(b)

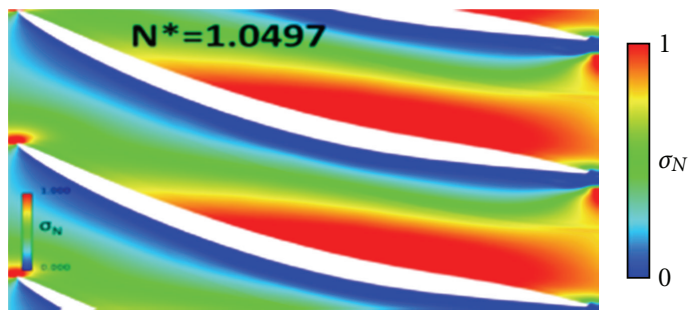

(d)

(B) Contours of local cavitation number, $\sigma_{N}=\left(p-p_{v}\right) /\left(\rho n^{2} D^{2}\right)$

Figure 9: Computational results, constant radius cut through rotor solution, $r / R_{\text {shroud }}=0.53$ (near hub), $Q^{*}=0.825$. Results at each of four conditions, (a) $\left(N^{*}=1.1149\right)(\mathrm{b})\left(N^{*}=1.0699\right)$ (c) $\left(N^{*}=1.0392\right)$ (d) $\left(N^{*}=1.0497\right)$, prior to and after breakdown. (A) Volume fraction contours. (B) Local cavitation number.

This conclusion is further supported in Figures 10-12. In Figure 10, a constant radius cut at $r / R_{\text {shroud }}=0.698$, is plotted. In Figure 11, a constant radius cut near the shroud, at $r / R_{\text {shroud }}=0.866$, is plotted. In Figure 12 another view of this comparison is presented. Here, local cavitation number colors a constant axial cut, near the exit of the rotor, that is, close to the hypothesized contraction. Note again that blue indicates a local saturated vapor flow. Again consider that the flow in Figure 12 has moved through a rotor at fixed rotation rate fed by a reservoir at fixed total pressure. Further consider the two conditions presented where saturated flow is evident at the rotor exit, the throat in this choked flow.
By conservation of energy, it is not possible to accelerate the flow without further increasing the region of saturated vapor, decreasing the effective flow area. Furthermore, given that the upstream total pressure and the absolute vapor pressure are fixed, the present flow rate cannot be maintained if the upstream total pressure is reduced. In each of these cases it is seen that the conditions coinciding with the presence of significant vapor at the trailing edge of the rotor blade (a saturated condition at the exit of the rotor passage), the waterjet flow is choked. Taken together Figures 8-12 present a clear picture of cavitation choking in the waterjet rotor, choking due to saturated conditions at the rotor passage exit. 


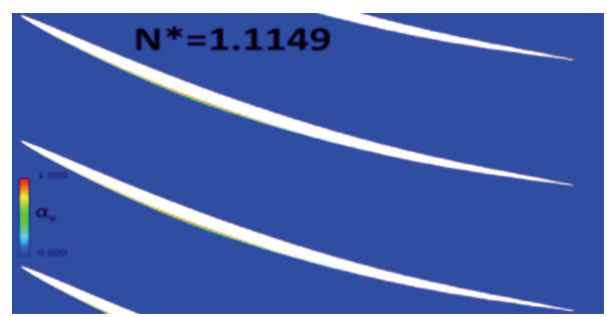

(a)

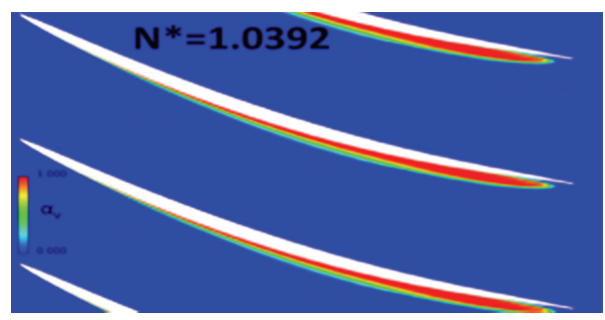

(c)

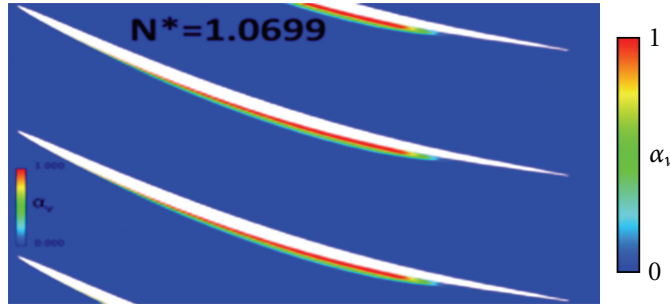

(b)

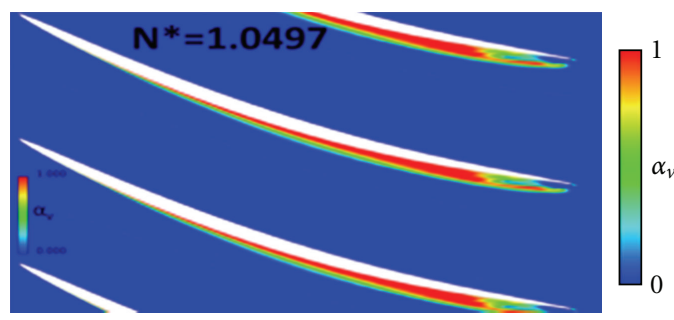

(d)

(A) Contours of vapor volume fraction

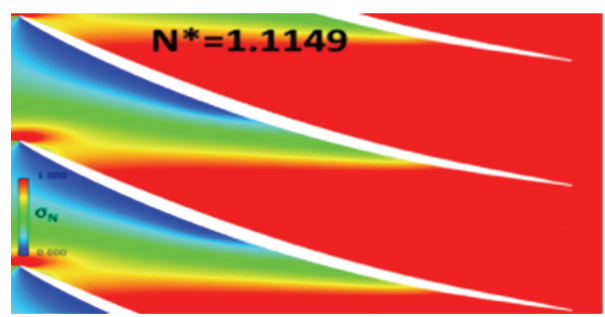

(a)

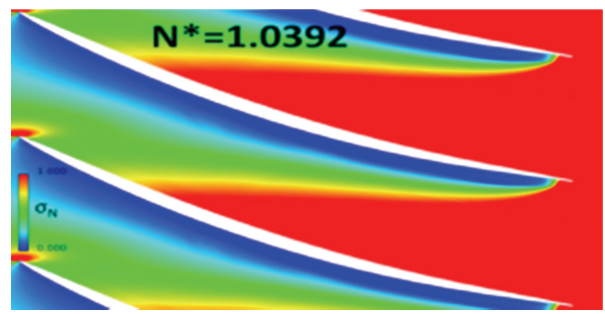

(c)

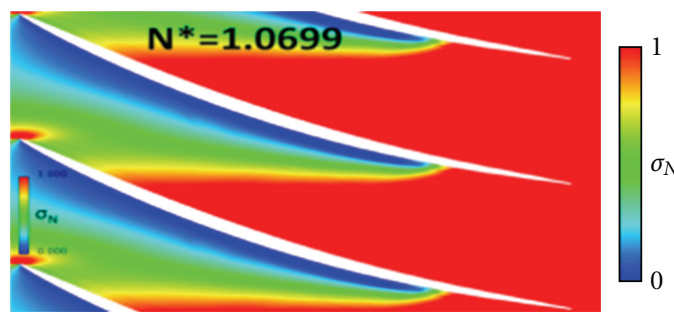

(b)

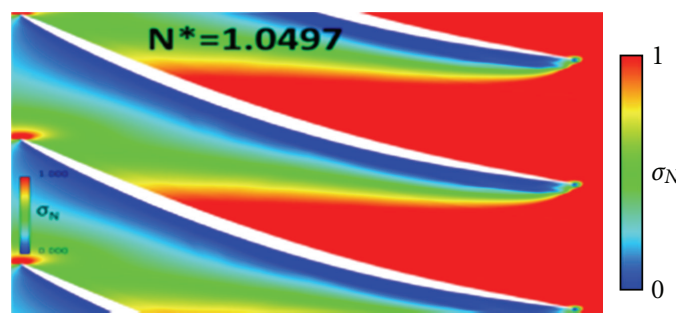

(d)

(B) Contours of local cavitation number, $\sigma_{N}=\left(p-p_{v}\right) /\left(\rho n^{2} D^{2}\right)$

FIGURE 10: Computational results, constant radius cut through rotor solution, $r / R_{\text {shroud }}=0.698$ (near mid span), $Q^{*}=0.825$. Results at each of four conditions, (a) $\left(N^{*}=1.1149\right)\left(\right.$ b) $\left(N^{*}=1.0699\right)(\mathrm{c})\left(N^{*}=1.0392\right)(\mathrm{d})\left(N^{*}=1.0497\right)$, prior to and after breakdown. (A) Vapor volume fraction contours. (B) Local cavitation number.

\section{Conclusions}

An axial flow waterjet in water-tunnel test configuration has been modeled using a powering iteration methodology. The flow was modeled over a range of conditions including cavitation breakdown. The single- and multiphase flow solutions appear to accurately capture the integrated performance at all conditions. In addition, the overall cavitation patterns, on rotor blade suction surface and due to tip-gap flows, were well captured at a range of cavitation conditions. For ducted devices, such as waterjets, it is suspected that flow breakdown will coincide with cavitation choking in the rotor passage. This is suspected in the experimental data and has been demonstrated in the computational results. As has been previously shown for unducted propulsors $[4,21]$, it appears that the present computational approach is useful 


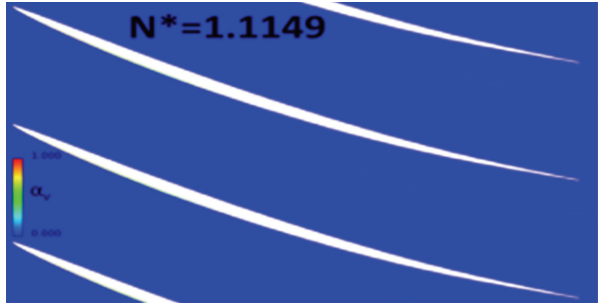

(a)

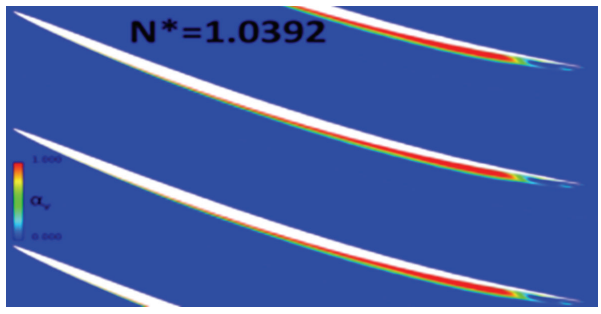

(c)

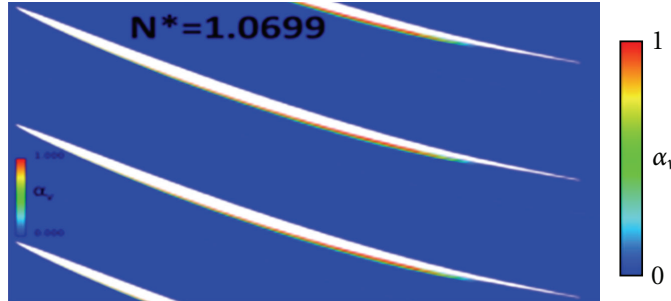

(b)

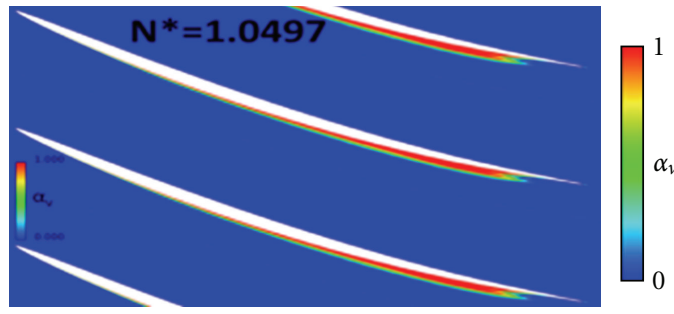

(d)

(A) Contours of vapor volume fraction

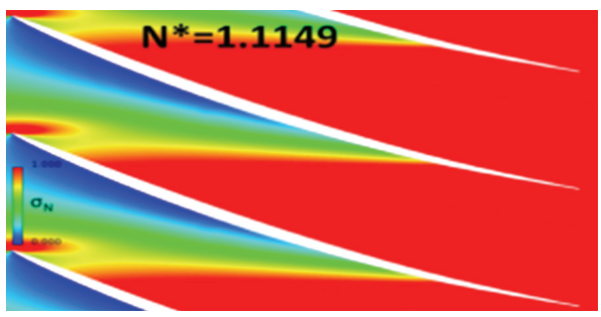

(a)

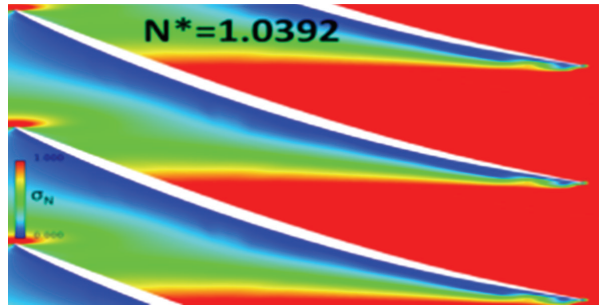

(c)

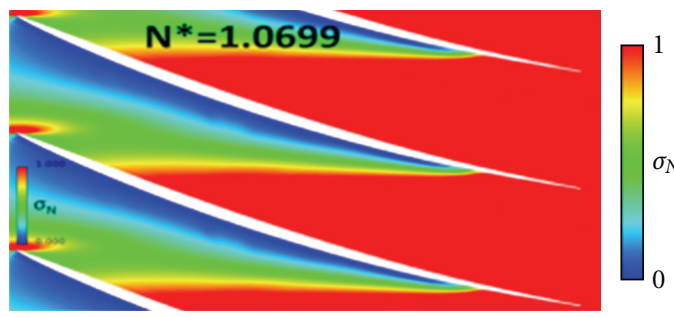

(b)

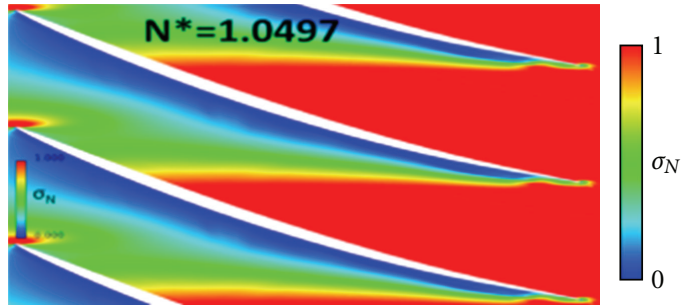

(d)

(B) Contours of local cavitation number, $\sigma_{N}=\left(p-p_{v}\right) /\left(\rho n^{2} D^{2}\right)$

FIGURE 11: Computational results, constant radius cut-through rotor solution, $r / R_{\text {shroud }}=0.866$ (near tip), $Q^{*}=0.825$. Results at each of four conditions, (a) $\left(N^{*}=1.1149\right)\left(\right.$ b) $\left(N^{*}=1.0699\right)(\mathrm{c})\left(N^{*}=1.0392\right)(\mathrm{d})\left(N^{*}=1.0497\right)$, prior to and after breakdown. (A) Vapor volume fraction contours. (B) Cavitation number.

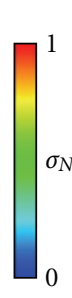

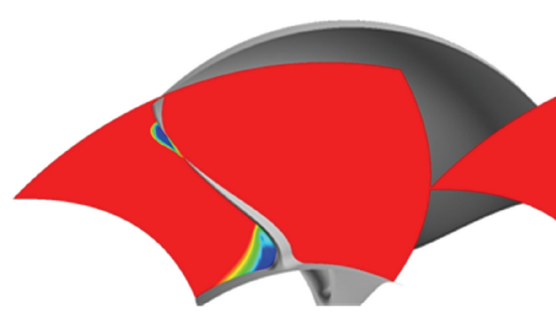

$N^{*}=1.0497$

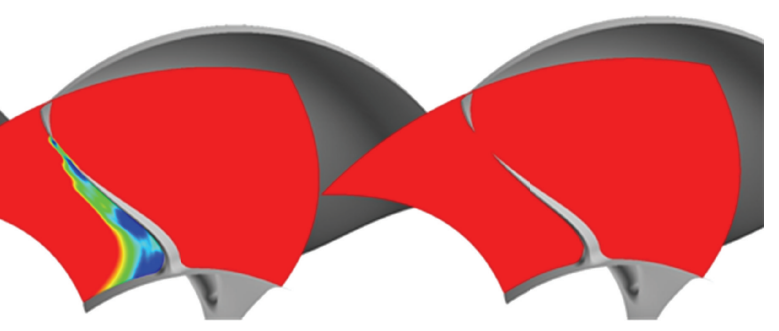

$N^{*}=1.0392$

$N^{*}=1.0699$

FIGURE 12: Computational results, local cavitation number, plotted on constant axial cut-through rotor solution at approximate rotor exit, $Q^{*}=0.825$. Results at each of three conditions of interest, $N^{*}=1.0497$ and 1.0392 in breakdown and 1.0699 prior to breakdown. 
and accurate when properly applied to the modeling of blade cavitation patterns and cavitation-driven thrust breakdown for axial flow waterjets.

\section{Acknowledgments}

This work was supported by the Office of Naval Research Grant no. N00014-09-1-0314 with Dr. Ki-Han Kim as program officer. Thanks are also extended to Martin J. Donnelly, Seth D. Schroeder, and Christopher J. Chesnakas of NSWCCD for provision and interpretation of experimental measurements.

\section{References}

[1] C. Mishra and Y. Peles, "Cavitation in flow through a microorifice inside a silicon microchannel," Physics of Fluids, vol. 17, no. 1, Article ID 013601, 2005.

[2] C. E. Brennen, Cavitation and Bubble Dynamics, Free Streamline Flows, chapter 8, Oxford University Press, New York, NY, USA, 1995.

[3] R. F. Kunz, D. A. Boger, D. R. Stinebring et al., "A preconditioned Navier-Stokes method for two-phase flows with application to cavitation prediction," Computers and Fluids, vol. 29, no. 8, pp. 849-875, 2000.

[4] J. W. Lindau, D. A. Boger, R. B. Medvitz, and R. F. Kunz, "Propeller cavitation breakdown analysis," Journal of Fluids Engineering, vol. 127, no. 5, pp. 995-1002, 2005.

[5] J. W. Lindau, W. L. Moody, M. P. Kinzel, J. J. Dreyer, R. F. Kunz, and E. G. Paterson, "Computation of cavitating flow through marine propulsors," in Proceedings of the 1st International Symposium on Marine Propulsors, Trondheim, Norway, 2009.

[6] M. M. Athavale, H. Y. Li, Y. U. Jiang, and A. K. Singhal, "Application of the full cavitation model to pumps and inducers," International Journal of Rotating Machinery, vol. 8, no. 1, pp. $45-56,2002$.

[7] O. Coutier-Delgosha, R. Fortes-Patella, and J. L. Reboud, "Evaluation of the turbulence model influence on the numerical simulations of unsteady cavitation," Journal of Fluids Engineering, vol. 125, no. 1, pp. 38-45, 2003.

[8] I. Mejri, F. Bakir, R. Rey, and T. Belamri, "Comparison of computational results obtained from a homogeneous cavitation model with experimental investigations of three inducers," Journal of Fluids Engineering, vol. 128, no. 6, pp. 1308-1323, 2006.

[9] S. Schroeder, "Toward predicting performance of an axial flow waterjet including the effects of cavitation and thrust breakdown," in Proceedings of the 1st International Symposium on Marine Propulsors, Trondheim, Norway, 2009.

[10] C. L. Merkle, J. Z. Feng, and P. E. O. Buelow, "Computational modeling of the dynamics of sheet cavitation," in Proceedings of the 3rd International Symposium on Cavitation, Grenoble, France, 1998.

[11] A. K. Singhal, M. M. Athavale, H. Li, and Y. Jiang, "Mathematical basis and validation of the full cavitation model," Journal of Fluids Engineering, vol. 124, no. 3, pp. 617-624, 2002.

[12] S. Venkateswaran, J. W. Lindau, R. F. Kunz, and C. L. Merkle, "Computation of multiphase mixture flows with compressibility effects," Journal of Computational Physics, vol. 180, no. 1, pp. 54-77, 2002.

[13] S. Venkateswaran and C. L. Merkle, Analysis of Preconditioning Methods for the Euler and Navier-Stokes Equations, VKI Lecture
Series 1999-03, Von Karman Institute, Rhode-Saint-Genese, Belgium, 1999.

[14] J. W. Lindau, S. Venkateswaran, R. F. Kunz, and C. L. Merkle, "Development of a fully-compressible multiphase reynoldsaveraged navier-stokes model," in Proceedings of the 15th AIAA Computational Fluid Dynamics Conference, Anaheim, Calif, USA, 2001.

[15] G. H. Schnerr, I. H. Sezal, and S. J. Schmidt, "Numerical investigation of three-dimensional cloud cavitation with special emphasis on collapse induced shock dynamics," Physics of Fluids, vol. 20, no. 4, Article ID 040703, 2008.

[16] T. S. Shih, L. A. Povinelli, N. S. Liu, M. G. Potapczuk, and J. T. Lumley, "A generalized wall function," NASA TM 1999209398, Glenn Research Center, Cleveland, Ohio, USA, 1999.

[17] K. S. Abdol-Hamid, B. Lakshmanan, and J. R. Carlson, "Application of navier-stokes code PAB3D with k-e turbulence model to attached and separated flows," NASA Technical Paper 3480, NASA Langley Research Center, Hampton, Virginia, 1995.

[18] D. C. Wilcox, Turbulence Modeling for CFD, DCW Industries, La Cañada Flintridge, Calif, USA, 1998.

[19] M. Morgut and E. Nobile, "Influence of the mass transfer model on the numerical prediction of the cavitating flow around a marine propeller," in Proceedings of the 2nd International Symposium on Marine Propulsors, Hamburg, Germany, June 2011.

[20] C. J. Chesnakas, M. J. Donnelly, D. W. Pfitsch, A. J. Becnel, and S. D. Schroeder, "Performance evaluation of the ONR axial waterjet 2 (AxWJ-2)," Hydromechanics Department Report 2009(089), Carderock Division, Naval Surface Warfare Center, 2009.

[21] J. W. Lindau, R. F. Kunz, V. Sankaran, D. R. Stinebring, and L. J. Peltier, "Development and application of turbulent, multiphase CFD to supercavitation," in Proceedings of the 2nd International Symposium on Seawater Drag Reduction, Busan, Korea, May 2005. 

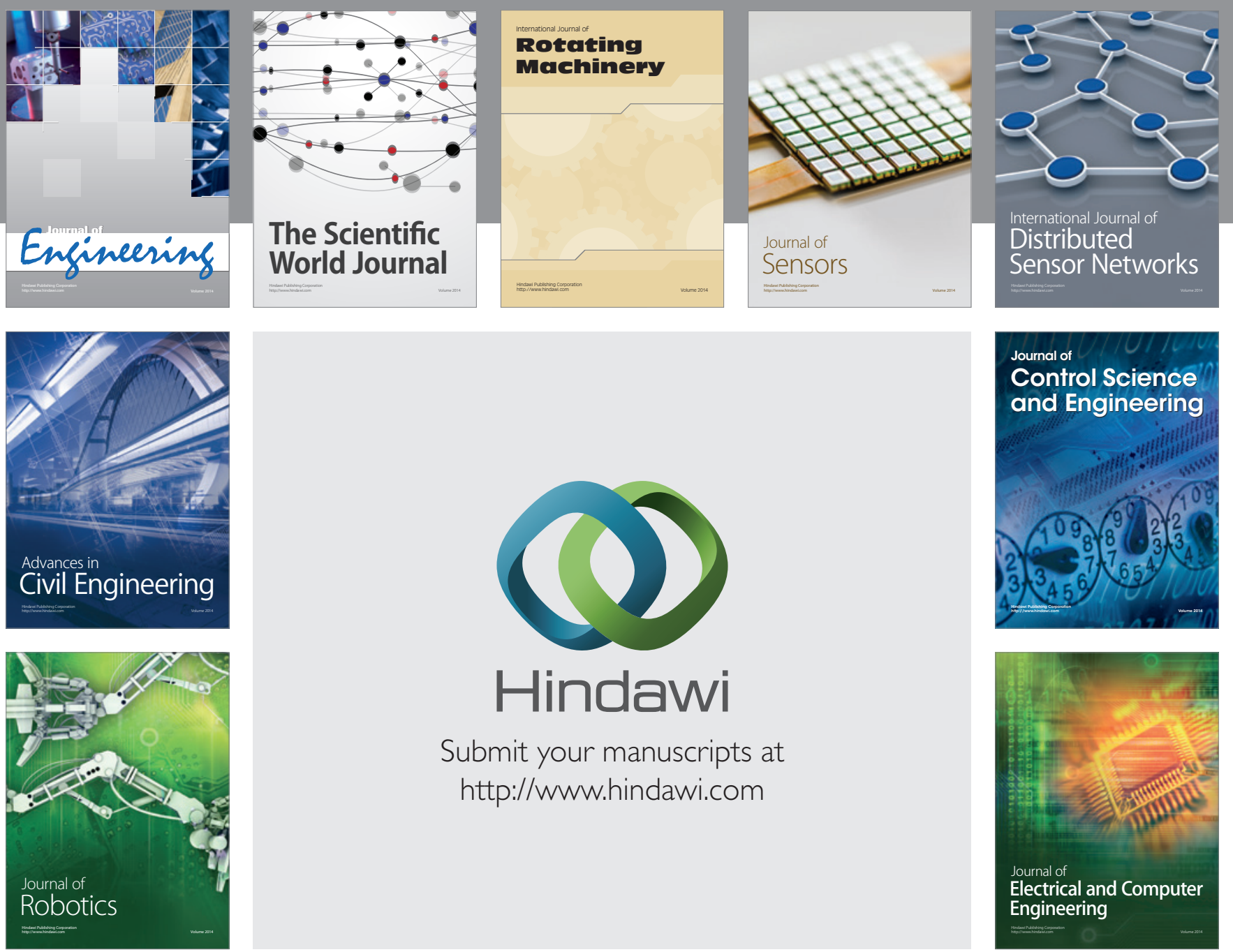

Submit your manuscripts at

http://www.hindawi.com
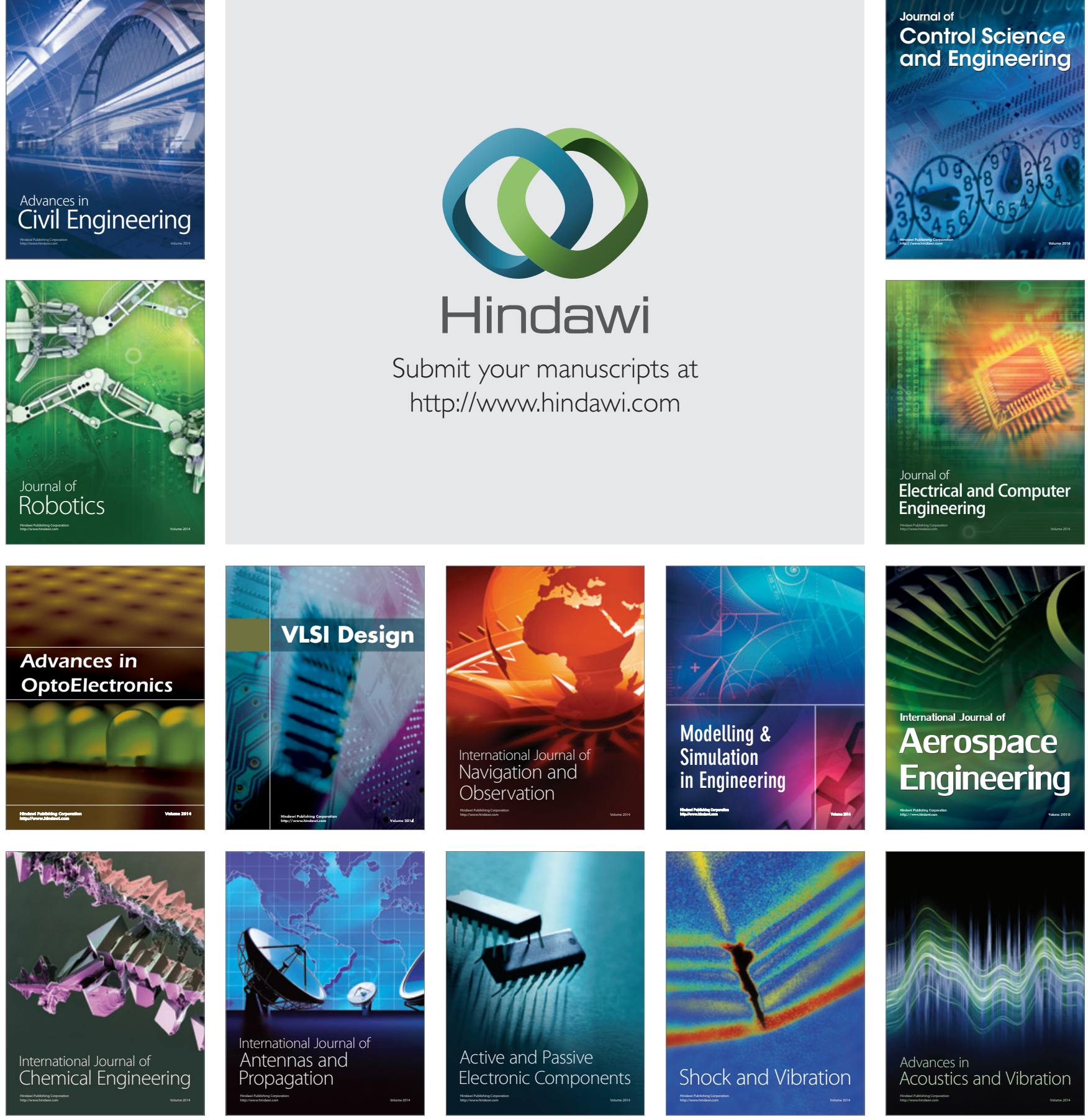